\title{
The Global Spread of Fertility Decline: Population, Fear, and Uncertainty
}

\author{
by Jay Winter and Michael Teitelbaum \\ New Haven, CT, and London: Yale University Press, 2013 \\ ISBN 978-0-300-13906-8 \\ Hardcover \$60, 336 pp.
}

\section{Reviewed by Md Kamrul Islam \\ University of Lethbridge}

Fertility decline around the world, with some exceptions in developing countries, presents an unprecedented challenge due to its wider impacts on labour force, economy, and population ageing. The declining trend in global fertility has been attributed mostly to economic and cultural factors by the first demographic transition theory and second demographic transition theory, respectively. However, politics has received limited attention in earlier scholarly contributions in examining fertility dynamics. The book Global Spread of Fertility Decline: Population, Fear and Uncertainty by Winter and Teitelbaum is certainly an important contribution to address the gap in the literature. The eight chapters of the book cover a wide range of topics, including globalization and demography, European population, the China trajectory, population and politics in India, family and fertility in Japan, and migration and fertility in North America. Throughout the book, the authors aim to establish the fact that we are living in a so-called "risk society," with continuous fear and uncertainty which exert a strong influence on the fertility behaviour of couples.

In the first chapter on Globalization and Demography, authors argue that declining fertility and rising international migration have become integral features of globalization. The two major waves of globalization (first from 1880 to 1914; and second from the mid-1980s to the present) were markedly influenced by political, military, economic, technological, and cultural forces, and had a powerful impact on the acceleration of global migration. The authors add that the second wave is also framed by the (semi-)globalization of fertility decline, with some exceptions in the Middle East and sub-Saharan Africa. For instance, the number of countries with fertility rates below the replacement level of 2.1 children per woman had increased to 64 by 2000-2005, from only 5 countries in 1960. Along with economic factors, political development has played important role in fertility decline of these countries. However, the declining trend in fertility has raised concern among governments and policymakers, due to its negative impact on labour force supply and increasing ageing population. For this reason, governments have introduced various intervention programs to increase fertility. Nonetheless, there is a big debate about the extent to which the programs are effective in increasing fertility.

Winter and Teitelbaum put forward the "risk hypothesis" by providing in-depth evidence from European countries, including Russia, Germany, Italy, Spain, and Greece in chapter 2. The hypothesis assumes that we are living in an era of uncertainty. In the era of second demographic 
transition-which is characterized by changes in norms and values related to marriage, family formation, and childbearing - higher risk of divorce and increasing rate of cohabitation have exacerbated the fear of risk among women in the case of childbearing, which eventually lead to sustained low fertility in European countries. Hence, the authors contend, "very low fertility or childlessness is a pathway to freedom, not defined by an infinity of choices but as a strategy of risk aversion" (p. 43). The presumed risk related to career, employment, and future security has been attributed to the political instability that prevailed throughout Europe during last century. The risk bypothesis suggests that changing patterns of family formation, political development, economic recessions, and cultural conflict are the sources of fear related to future security. Given that the risk hypothesis was not tested empirically, future research on global fertility should focus on testing it rigorously, with a view to having reliable evidence to justivy possible policy interventions.

The third chapter (on Islam in Europe) provides a critical reflection on the emergence of Islamophobia and its manifestations across Europe, citing evidence from the debates on the veil in France, the murder of Theodoor van Gogh in Holland, conflict regarding Danish political cartoons, enacting laws on preventing minarets in Switzerland, and violence against Muslims across Europe. This section provides better insight into uses and abuses of the term Islamophobia, along with the extent to which it has become challenging to ensure peace and stability in the multicultural context. The authors suggested a "human rights framework" for understanding the dynamics of Muslims' presence in Europe. The authors very rightfully disagree with the perception that "the Muslims already in Europe will outbreed their non-Muslim neighbors and take over the continent by demographic default" (p. 108). There is evidence that fertility of immigrants and their second-generation descendants is even lower compared to the native-born population of the host society (Milewski 2010).

Presenting a separate section on the "China trajectory" is worthwhile because China is an exceptional case of fertility decline; there, politics were at the forefront in strictly implementing its "one-child policy," with some exceptions. This policy further accelerated the already declining trend of fertility from more than 6.0 children per woman in the 1960s to 1.38 children in 2002. The United Nations (2017) projections show that the TFR in China will remain much below the replacement level of 2.1 children per woman even after 2050, raising new challenges in areas of labour force, population aging, imbalanced sex ratio at birth, and the economy. Now the government of China has relaxed the one-child policy and introduced a two-child policy in 2015. Despite changing the one-child policy, data from the National Bureau of Statistics showed declining number of births in 2017, which raises the question of whether introducing a two-child policy will lead to a sustained increase in the total fertility rate that reaches above-replacement fertility. The biggest challenge here is that similarly to social change, fertility behaviour of couples changes gradually; therefore, changes in policy may not bring the desired increase in fertility as quickly as expected by government officials.

The chapter on population and politics in India focuses on political developments along with economic factors to explain differences in pathways of fertility decline in different regions in the same country. At the aggregate level, India's fertility has fallen from 4.97 children per woman during 1975-2000 to 2.3 for the current period of 2015-20, and it is projected to go down to 2.1 by 2025-30 and 1.78 during 2095-2100. The authors show that with the exception of a few states (e.g., Punjab, Himachal Pradesh, Andhra Pradesh, and Kerala), fertility rates are still at above-replacement level in most states, suggesting that the top-down policy for controlling fertility has failed in India; thus, the case of China may have been an exception. 
Japan is another unique example of the global spread of fertility decline, though its context is different from China and India. In the chapter "Japan: Family and fertility since 1945," the authors show that the total fertility rate in Japan was 4.3 in 1949, which declined to 1.39 in 2011 . The sustained declining trend in fertility rate has been attributed to various interventions by the government, such as enacting laws for delaying the age of entry into sexual union, supporting increased use of contraception, and facilitating large-scale induced abortion and breastfeeding practices. To justify Japan as one of the examples of a "risk society," the authors argue that "young professional women see childbearing as a risk, endangering their prospective careers and financial security" (p. 190). In addition, the ultimate consequences of urbanization - such as the development of individualism, small family size, considering marriage as a sine qua non for having children, and the desire for quality children — should be taken into account in explaining the fertility decline in Japan.

The last chapter, on "North America and NAFTA," provides a contrasting scenario of fertility in Canada, USA, and Mexico. Fertility in Canada and USA declined substantially after the baby boom of the 1950s, but Mexico's fertility remained high for decades despite its socio-economic development, urbanization, and industrialization. In fact, Mexico's government encouraged high fertility during the 1960s, motivating by the slogan "to govern is to populate" (p. 210). In contrast, in the 1970s the government of Mexico emphasized population control by introducing family planning programs, fearing the negative impact of population growth on economic development. Thus, in both cases political development was at the centre of either increasing fertility or declining fertility. Further attention is needed to justify the extent to which the USA and Mexico resemble "risk societies" in terms of childbirth, given the fact that despite the prevailing tension and anxiety among Mexican immigrants in the USA, their fertility rates are usually higher than those of other Americans.

In sum, the authors cover a wide range of historical information on politics, health care, economy, and migration policy in providing plausible explanations for fertility decline. And this is what makes the book important for scholars, including historians, political scientists, demographers, health experts, and policy makers. Another powerful feature of the book is its inclusion of convincing evidence on fertility decline both from developed and developing countries, and its elaboration of a "risk hypothesis" framework for explaining fertility decline. Future research should focus on examining the extent to which fertility dynamics of African countries-which are still characterized by high fertility, persistence poverty, and political instability - fit into the new framework of risk hypothesis proposed by the authors in this book.

\section{References}

Milewski, N. 2010. Fertility of Immigrants: A Two-Generational Approach in Germany. Berlin-Heidelberg: Springer-Verlag.

United Nations. 2017. World Population Prospects: The 2017 Revision, Key Findings and Advance Tables. Working Paper No. ESA/P/WP/248. New York: UN Department of Economic and Social Affairs, Population Division. 